\title{
A Junctional Rhythm Caused by Administration of Intravenous Phenytoin
}

\author{
Güllü Akbaydoğan Dündar (D), Ibrahim Toker (D), Hüseyin Narcl (D), Cüneyt Ayrık (D \\ Department of Emergency Medicine, Mersin University School of Medicine, Mersin, Turkey
}

Cite this article as: Akbaydoğan Dündar G, Toker I, Narcı H, Ayrık C. A Junctional Rhythm Caused by Administration of Intravenous Phenytoin. J Emerg Med Case Rep 2018; 9: 10-2.

\begin{abstract}
Introduction: We present the case of a patient with symptomatic junctional rhythm caused by administration of intravenous phenytoin. However, bradycardia and hypotension are more commonly associated with rapid infusion of intravenous phenytoin. In our patient, the rate of intravenous phenytoin administration was $<50 \mathrm{mg} / \mathrm{min}$.

Case Report: A 79-year-old woman presented to the emergency department with altered mental status for $2 \mathrm{~h}$ and focal seizure. After phenytoin was intravenously infused over 45 min, junctional rhythm, unresponsiveness, and hypotension developed. Atropine, dopamine, and transcutaneous pacing were initiated. After the intervention, a normal sinus rhythm with a normal heart rate was maintained. The patient was admitted to the neurological intensive care unit.

Conclusion: Emergency physicians should monitor patients for possible arrhythmic effects of intravenous phenytoin therapy. In addition to geriatric patients and patients with a history of cardiac disease, there may be an increased risk of cardiotoxicity for phenytoin even at the recommended dose and infusion rate in patients with end-stage renal disease.
\end{abstract}

Keywords: Bradyarrhythmias, phenytoin, cardiotoxicity

Received: 02.06.2017 Accepted: 14.07.2017

\section{Introduction}

Phenytoin is an anticonvulsant drug used for treating many seizure disorders. It is also a class IB anti-arrhythmic agent, although it is now infrequently used for that indication. Rapid administration of intravenous phenytoin can cause hypotension, bradyarrhythmias, and occasional asystole $(1,2)$. In this case report, we aimed to validate that phenytoin can cause cardiotoxicity even at the recommended dose and infusion.

\section{Case Report}

A 79-year-old woman presented to the emergency department with an altered mental status for $2 \mathrm{~h}$ and focal seizure (tonicclonic movement of the right upper limb). Her medical history included end-stage renal disease for which she was on hemodialysis, type 2 diabetes mellitus, hypertension, coronary artery disease, and a history of brain tumor surgery. Her home medications included levetiracetam, clopidogrel, carvedilol, and gabapentin.

The patient's weight was $68 \mathrm{~kg}$, and her vital signs on admission were a temperature of $36.6^{\circ} \mathrm{C}$, blood pressure of 150/71 mm/ $\mathrm{Hg}$, heart rate of 117 beats/min, and respiratory rate of 20 breaths/min, and her oxygen saturation was $91 \%$ while breathing room air. Her Glasgow Coma Scale was 12, and she appeared apathetic. The remaining physical examination results were normal. Laboratory findings on admission were hemoglobin level of $8 \mathrm{~g} / \mathrm{dL}$, serum sodium level of $137 \mathrm{meq} / \mathrm{L}$, potassium level of 5.34 meq/L, glucose level of $112 \mathrm{mg} / \mathrm{dL}$, creatinine level of $9.29 \mathrm{mg} / \mathrm{dL}$, and urea level of $162.7 \mathrm{mg} / \mathrm{dL}$. On blood gas analysis, the pH

Address for Correspondence:

İbrahim Toker, Department of Emergency Medicine, Mersin University School of Medicine, Mersin, Turkey

E-mail: ibrahimtoker9@gmail.com

c Copyright 2018 by Emergency Physicians Association of Turkey - Available online at www.jemcr.org 


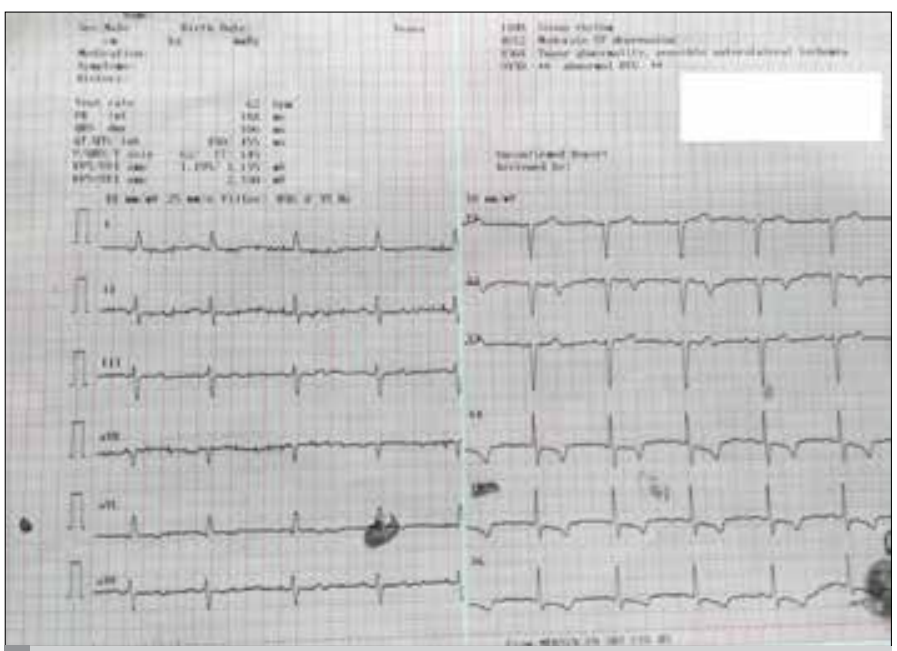

FIGURE 1. ECG showed a normal sinus rhythm

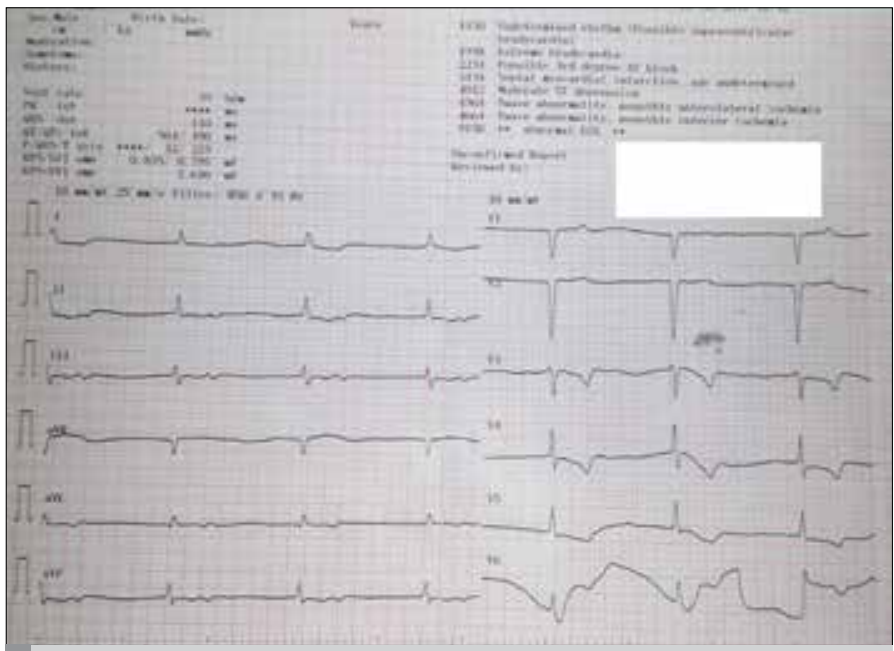

FIGURE 2. ECG showed junctional bradycardia

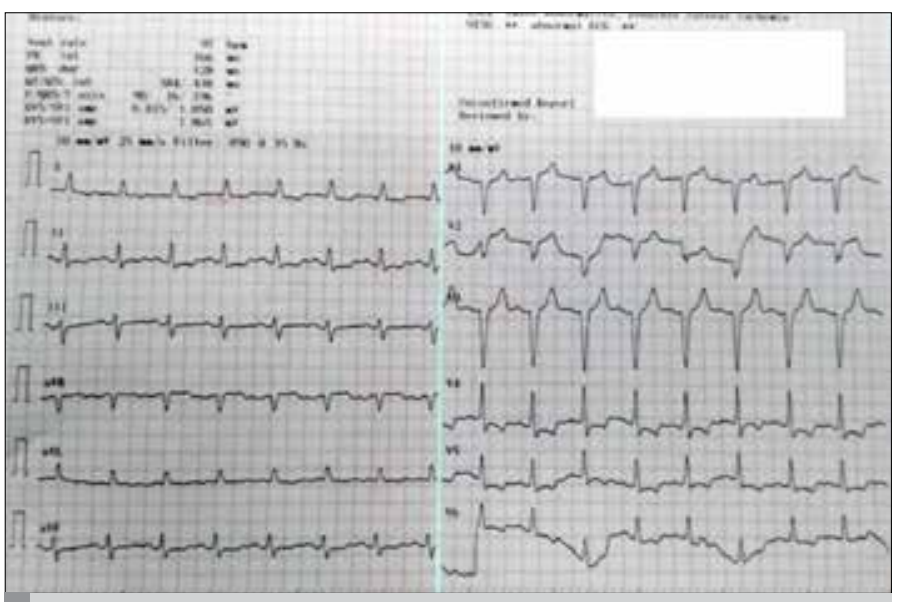

FIGURE 3. ECG showed a normal sinus rhythm after interventions

was 7.27, $\mathrm{pCO}_{2}$ was $38.6 \mathrm{mmHg}, \mathrm{pO}_{2}$ was $69 \mathrm{mmHg}, \mathrm{HCO}_{3}$ was 17.7 $\mathrm{mmol} / \mathrm{L}$, base excess was -8 , and oxyhemoglobin rate was $87.5 \%$. No abnormalities were detected on initial brain computed tomography
(CT). An initial electrocardiogram (ECG) revealed sinus rhythm with a heart rate of 62 beats/min (Figure 1). After neurology consultation, $1000 \mathrm{mg}$ phenytoin (loading dose of $15 \mathrm{mg} / \mathrm{kg}$ ) in $250 \mathrm{~mL}$ of saline was intravenously infused over 45 min (infusion rate was in $22.2 \mathrm{mg} /$ min and the concentration of phenytoin was $4 \mathrm{mg} / \mathrm{mL}$ ).

Immediately after phenytoin infusion, ECG showed junctional bradycardia with a heart rate of 39 beats/min (Figure 2). The patient became unresponsive, and hypotension developed (blood pressure of $93 / 51 \mathrm{mmHg}$ ). Atropine (0.5 mg IV push) was administered immediately and repeated two times. Because of continued bradycardia and hypotension, transcutaneous pacing was initiated. Dopamine infusion was concurrently started at $10 \mu \mathrm{g} / \mathrm{kg} / \mathrm{min}$. The patient subsequently improved hemodynamically and neurologically, resulting in discontinuation of dopamine infusion and transcutaneous pacing. Fifteen minutes after the intervention, his ECG showed a normal sinus rhythm with a heart rate of 97 beats/min (Figure 3). The patient was admitted to the neurological intensive care unit.

\section{Discussion}

In this case, we present an example of a patient with phenytoin cardiotoxicity resulting in junctional bradycardia. This case is important because it shows that phenytoin can cause toxicity even though it is administered at the recommended dose and at a low infusion rate.

Phenytoin is an effective anticonvulsant that is used for partial and tonic-clonic seizures. Because phenytoin is used in the oral and parenteral form and it can rapidly reach emergency treatment levels, it is used as a first-line drug therapy for managing seizures in the emergency department. The main side effects of phenytoin are gingival hyperplasia, hirsutism, acne, and facial coarsening (3).

Two variables may be responsible for phenytoin toxicity: total dose and the rate of administration. Recommendations for phenytoin administration are shown Table 1 (1). In a review article, administering phenytoin at a slow rate $(25 \mathrm{mg} / \mathrm{min})$ for status epilepticus is recommended in geriatric patients and patients with known cardiovascular disease (4). In our patient, we infused phenytoin at a rate of 22.2 $\mathrm{mg} / \mathrm{min}$ and the total dose was $15 \mathrm{mg} / \mathrm{kg}$.

Phenytoin binds to the plasma protein at a high level (approximately 90\%), and the free part is responsible for the pharmacological effects. Therefore, unbound serum phenytoin is high in patients with hypoalbumin or end-stage renal disease (5). Several equations have been developed for calculating free phenytoin concentration, and only albumin and total phenytoin concentrations were correlated with the free phenytoin concentration (6). Our patient had endstage renal disease for which she was on hemodialysis. In our hospital's medical records, we found that our patient had a low albumin level $(<3.4 \mathrm{~g} / \mathrm{dL})$ for the past 2 years. However, we did not measure the patient's albumin level on admission.

Propylene glycol is a commonly used solvent in various intravenous drug preparations, and it can also produce toxicity. Propylene glycol toxicity causes high anion gap metabolic acidosis. However, propyl- 
Table 1. Recommendations for phenytoin administration

$\begin{array}{ll}\text { IV solution } & \text { 1. The concentration of phenytoin should be } \leq 6.7 \mathrm{mg} / \mathrm{mL} \\ & \text { 2. Infusion rate at } \leq 40 \mathrm{mg} / \mathrm{min} \\ \text { 3. Infuse only through a free-flowing, well-positioned IV needle } \\ \text { 4. Infuse via piggyback IV arrangement }\end{array}$

ene glycol toxicity is more common with lorazepam infusion. Phenytoin infusion should also be considered (7).

\section{Conclusions}

Emergency physicians should monitor patients for possible arrhythmic effects of intravenous phenytoin therapy. Additionally, geriatric patients and patients with history of cardiac disease may have an increased cardiotoxicity risk with phenytoin administration even if the recommended dose and infusion rate in patients with end-stage renal disease.

Informed Consent: Not required in this study.

Peer-review: Externally peer-reviewed.

Author Contributions: Design - H.N.; Supervision - I.T., G.A.D.; Data Collection and/or Processing - G.A.D., H.N.; Analysis and/or Interpretation - C.A.; Literature Search - C.A., H.N.; Writing Manuscript - I.T., G.A.D.; Critical Review - H.N.

Conflict of Interest: No conflict of interest was declared by the authors.
Financial Disclosure: The authors declared that this study has received no financial support.

\section{References}

1. Earnest MP, Marx JA, Drury LR. Complications of intravenous phenytoin for acute treatment of seizures. Recommendations for usage. Jama 1983; 249: 762-5. [CrossRef]

2. Phenytoin poisoning [Internet]. Uptodate Wolters Kluwer. 2016 [cited 30.01.2017]. Available from: https://www.uptodate.com/contents/ phenytoin-poisoning?source=search_result\&search=phenytoin $\% 20$ toxicity\&selectedTitle $=1 \sim 35$.

3. Hung OL, Shih RD. Antiepileptic drugs: the old and the new. Emerg Med Clin North Am 2011; 29: 141-50. [CrossRef]

4. Khoujah D, Abraham MK. Status Epilepticus: What's New? Emerg Med Clin North Am 2016; 34: 759-76. [CrossRef]

5. Richens A. Clinical pharmacokinetics of phenytoin. Clin Pharmacokinet 1979; 4: 153-69. [CrossRef]

6. Cheng W, Kiang TK, Bring P, Ensom MH. Predictive Performance of the Winter-Tozer and Derivative Equations for Estimating Free Phenytoin Concentration. Can J Hosp Pharm 2016; 69: 269-79. [CrossRef]

7. Pillai U, Hothi JC, Bhat ZY. Severe propylene glycol toxicity secondary to use of anti-epileptics. Am J Ther 2014; 21: e106-9. [CrossRef] 